\title{
MUTUAL READING TECHNIQUE
}

\author{
Carmen Maria CHISIU, Ph.D., \\ „L. Blaga" University from Sibiu \\ carmenmariachisiu@yahoo.com \\ carmenmaria.chisiu@ulbsibiu.ro
}

\begin{abstract}
The concept of Mutual Reading was born of a need to increase participation in the learning activity of ALL students, not just a few, those with a sustained pace in solving school tasks, those with an increased need for affirmation. Mutual reading is a technique that can be used as a current assessment method whenever students perform an individual activity. The technique of mutual reading stimulates and creates conditions for the participation of all students in didactic activity, supports interactivity, is strongly activating, enhances self-esteem, facilitates and provokes learning. The paper provides some examples and recommendations for the efficient use of mutual read technique. Also, the paper includes the results of a research, results that confirm the value of this didactic technique.
\end{abstract}

Keywords: mutual reading; interactivity; continuous evaluation; individual work;

\section{Introduction}

The technique of mutual reading is a pedagogical concept that designates a working technique that can be used in school / academic learning after each sequence of independent activity, with the aim:

- to share with colleagues in the small group the way to solve individually;

- to express, at the level of the small group, the way of solving a problem, his own opinion, a personal opinion;

- to have a first evaluation of the learning outcomes, by confronting the solutions, the opinions, the others' opinions. 


\section{A short research}

We started from the hypothesis that mutual reading stimulates and creates the educational context for the participation of all students in the course activity and implicitly facilitates and provokes learning.

A questionnaire was provided to students through Google Drive. It was completed by 102 students attending pedagogical courses where the technique of mutual reading is frequently used. The questionnaire contains 10 questions, of which 2 refer to the technique of mutual reading:

1. Check the techniques you consider facilitate learning in the activities of the pedagogy course.

2. Give value to each other's reading (small group reading, what each person did, by individual work; (1 useless - 5 very useful);

We also used direct observation as a research method.

All the students that participated to the research chose the mutual reading technique as being one that facilitates learning and 4.1 is the average obtained by it as a degree of appreciation of the learning facilitating level.

Following direct participatory obervation, it can be appreciated that mutual reading as a working technique made all the students present to achieve the theme and then expressed their opinion / how to solve the problem solved by individual work.

By using mutual reading, it has been eliminated, the possibility that some of them, in the tendency to remain in the comfort zone, may indulge in the situation of passive participation in the activity. The technique put every student in the position of being listened, which motivated them.

The students' appreciations at the end of the courses, referring to the mutual reading, mention: the interactive, stimulating nature of the activities, the increased interest, the involvement, the specialized language skills, the attractiveness, the dynamism, the increase of the self-esteem, the imperceptible transition of time.

The results obtained by interpreting the answers to the questionnaire, the conclusions of the participatory direct observation of the teacher researcher and the students' assessments confirm the hypothesis that the technique of mutual reading stimulates and creates conditions for the participation of all students in the activity from the course and implicitly facilitates and provokes learning.

Following the results of the short research, we will try to bring examples of good practices, which the teacher can use in didactic activity to maximize the efficiency of the mutual reading technique. 


\section{Examples of good practice}

\section{Example I}

1. Divide the class into working groups of four or five students according to the class.

2. Pupils solve an exercise or answer a few questions through individual activity.

3. After working time is up, individually, each student reads the other colleagues in the small group what he has written.

4. For a few minutes, depending on the complexity of the task, the solutions, the results or the personal opinions formulated are discussed in the small group.

5. The points of view they disagree with in the small group can become topics of discussion for the whole class through frontal activity.

\section{Example II}

1. The activity takes place in pairs.

2. Students solve an exercise or answer a few questions individually.

3. After the working time is up, through individual activity, each explains the other, the way of solving. At the same time, with a coloured pencil, he makes the correction of his own mistakes, under the observation and direct involvement of his colleague.

4. Then the roles change.

5. At the end of the sequence, each performs self-evaluation, correction, identification of the cause that has generated the mistake and the correct way to solve it.

6. By a metacognition exercise, he analyses the solution, the steps, the errors and the way the tasks of that type can be solved in order to avoid mistakes.

\section{Recommendations for a good functioning:}

1. Announce students that, at the end of their individual work, they will make mutual reading. This will make them work with more responsibility, from the need to have what they share with colleagues, according to social observation theory.

2. Provide those with communication and relationship problems the possibility to choose the colleague they want to work with.

3. It can be used to carry out ongoing evaluation whenever there is an individual activity.

4. Give special time to reflection and metacognition: How did I manage to work correctly? Why didn't I reach the desired result? What else should I do? 
Journal Plus Education, ISSN: 1842-077X, E-ISSN (online) 2068-1151 Vol XIX (2018), No. 1. pp. 220-224

\section{Conclusions}

As a result of the use of this technique, over time, the psychodidactical reflections made with thousands of participants trainee in projects such as: Mentoring for Rural Teachers, Studium, Professionals for Afterschool, teachers participating in the preparation for obtaining the didactic degrees, students as future teachers, from the conclusions of focus groups organized during the pedagogical meetings, the mentor teachers' working sessions, the advantages identified are:

1. Each student will have his time when he is listened to by colleagues. He will feel useful and important, which will contribute to the development of his self-esteem.

2. It takes a little time and ensures the participation of each student in the activity. Nobody is excluded.

Each has his own moment of expressing his personal point of view, of his own way of solving. A first evaluation is carried out. It provides the possibility of displaying the learning results of each student. Some of the errors are identified by confronting responses, opinions, and shared ways of solving.

3. The differences of opinion, the different ways of solving give the pretext for group discussions on the given topic.

4. It ensures time multiplying. At the same time, in the classroom / course, by matching the intensity of the voice to the specifics of the work in the small group. Students speak in a number equal to the number of working groups. If we use classical frontal activity to evaluate the outcomes of individual activity, some students, 2-3, share their opinions, achievements; usually those who finish first. The risk is that, as a matter of course, a large number of students may no longer carry out the exercise for individual work because they know they will not be listened. Under these conditions, for many students, that time is a lost one because they did nothing.

\section{References}

Burke Walsh, K. (1998). Creating classes targeted needs children 8-9-10 years CEDP Step by Step. Bucharest.

Cerghit, I. (2003). Alternative and complementary Training Systems. Aramis Publishing House. Bucharest.

Chișiu, C., M., (2016). A student oriented school. The student, an active partner in his own learning process. Lambert Academic Publishing. Saarbrücken.

Chişiu, C.M. (2011). Pedagogy. Theory and Training Methodology. Assessment Theory and Methodology, Course Notes. "Lucian Blaga" University of Sibiu Publishing House. Sibiu. 
Journal Plus Education, ISSN: 1842-077X, E-ISSN (online) 2068-1151 Vol XIX (2018), No. 1. pp. 220-224

Popa C., M., (2007). The Interactive Lecture, an Alternative in the Universe, The 31st ANNUAL CONGRESS OF THE AMERICAN ROMANIAN ACADEMY OF ARTS AND SCIENCES, Pro-active partnership in creativity for the next generation, Presses internationals Polytechnique Constance Forest Directrice, CP6079, Succ. Center-ville bur.B-528.8 Montreal (Quebec) H3C 3A7 Canada, The National Library Quebec Canada, conference volume organized by ARA, professional society, pp. 618-621.

Popa, C., M., (2009). A Student-Centered School. The Student, an Active Partner in the Learning Process, Aramis Publishing House. Bucharest.

Steiner, R. (2001). Art Education. Methodology and Teaching (second edition). Triads Publishing House. Cluj - Napoca. 